\title{
Bezoar formation and obstruction caused by a surgical nylon thread after gastric bypass surgery
}

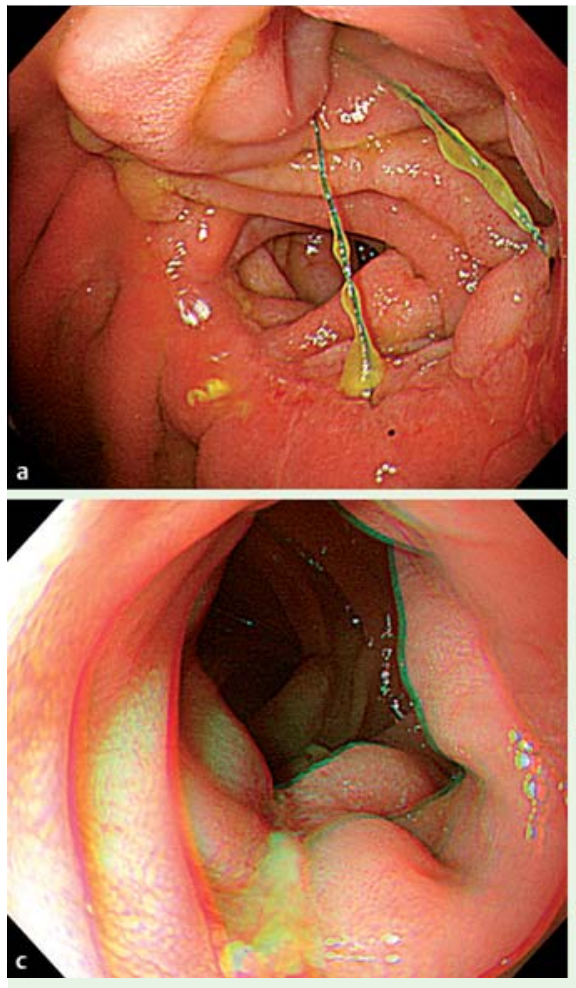

Fig. 1 Endoscopic views in a 58-year-old man who had recently undergone laparoscopy-assisted distal gastrectomy with Billroth II anastomosis showing: $\mathbf{a}$ a tense nylon surgical thread leading towards the efferent loop at the site of the anastomosis; $\mathbf{b}$ a bezoar that was found dangling at the end of the thread when it was pulled back into the gastric lumen; $\mathbf{c}$ a linear compression ulcer that had been induced by the thread in the efferent loop; $\mathbf{d}$ the bezoar being successfully removed using a net after the thread had been detached from the site of the anastomosis.

A 58-year-old man presented with postprandial pain that radiated to the right shoulder and right flank. He had undergone a laparoscopy-assisted distal gastrectomy with Billroth II anastomosis 2 months previously for Borrmann type III advanced gastric cancer. The operation had been uneventful and he had been discharged without any complications. However, about a week after being discharged he developed abdominal discomfort that worsened after eating. Because of the progressive postprandial

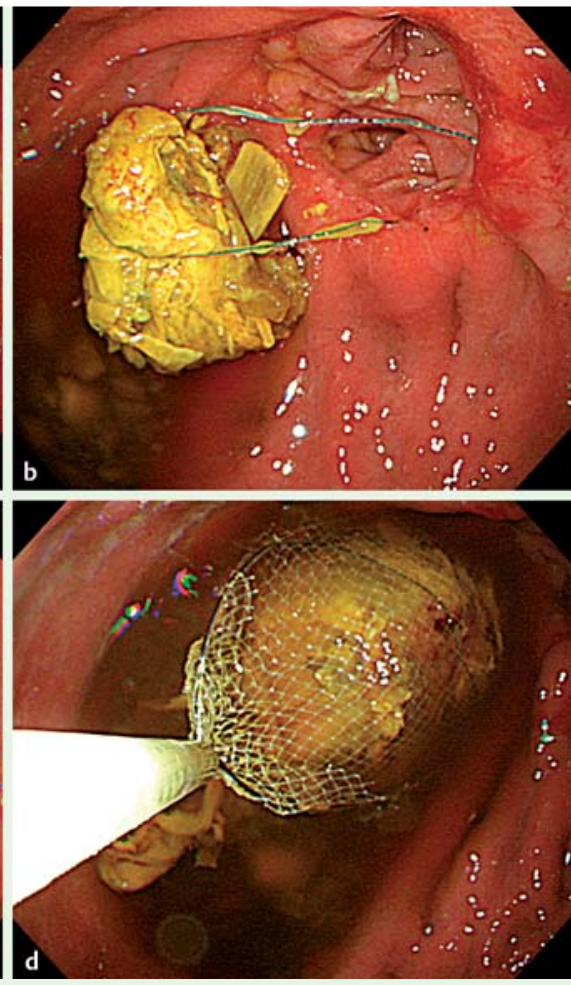

An upper gastrointestinal endoscopy was therefore performed to evaluate the cause of his abdominal pain. During this procedure, a remnant nylon thread that looked quite taut was seen leading into the efferent loop from the site of the anastomosis ( $\bullet$ Fig. 1a). When the thread was pulled back into the gastric lumen using biopsy forceps, food material was found stuck to the end ( Fig. 1 b). Linear ulceration was noted along a line where the thread had compressed and eroded the mucosa of the efferent loop ( $\bullet$ Fig.1 c). The thread was detached from the site of the anastomosis using biopsy forceps and the bezoar was then removed with a net ( $\bullet$ Fig. $1 \mathrm{~d}$ ). After the thread and attached bezoar had been removed, the patient no longer complained of postprandial pain.

\section{Endoscopy_UCTN_Code_CPL_1AH_2AK}

Competing interests: None

\section{Hyo Sung Kang, Jong Jin Hyun, Seung Young Kim, Sung Woo Jung, Ja Seol Koo, Hyung Joon Yim, Sang Woo Lee}

Division of Gastroenterology and Hepatology, Department of Internal Medicine, Korea University College of Medicine, Seoul, South Korea

Bibliography

DOI http://dx.doi.org/

10.1055/s-0033-1344991

Endoscopy 2013; 45: E412

(c) Georg Thieme Verlag KG

Stuttgart · New York

ISSN 0013-726X

abdominal pain, which was unrelated to gastric dumping syndrome or blind loop syndrome, his oral intake had reduced and he had lost $6 \mathrm{~kg}$ since the time of the operation.

When he was seen again, his physical examination revealed mild epigastric tenderness. His chest and abdominal radiographs were normal and an abdominal ultrasound was also unremarkable. His laboratory tests were all normal except for mild anemia.

\section{Corresponding author}

\section{Jong Jin Hyun, MD, PhD}

Division of Gastroenterology and Hepatology

Korea University Ansan Hospital

Gyeonggi-do, 425-707

South Korea

Fax: +82-31-4125582

sean4h@korea.ac.kr
Department of Internal Medicine

123, Jeokgeum-ro, Danwon-gu, Ansan-si 